\title{
DIGNIDADE DA PESSOA HUMANA, AUTONOMIA DE VONTADE E DIREITO DE COMUNICAÇÃO: ESTUDO DO CASO DAS PROVAS VEXATÓRIAS NOS REALITY SHOWS
}

\author{
DIGNITY OF THE HUMAN PERSON, AUTONOMY OF WILL AND RIGHT OF \\ COMMUNICATION: CASE STUDY OF THE VEXATIOUS TESTS IN THE REALITY \\ SHOWS
}

Emerson Affonso da Costa Moura

\begin{abstract}
Doutor em Direito pela Universidade do Estado do Rio de Janeiro (UERJ).Mestre em Direito Constitucional e Especialista em Direito da Administração Pública pela Universidade Federal Fluminense (UFF). Graduado em Direito pela Universidade Federal do Rio de Janeiro (UFRJ). É professor de Direito Administrativo no Curso Preparatório da Escola de Magistratura do Estado do Rio de Janeiro (EMERJ), Curso da Escola Superior de Advocacia (ESA/OAB) e Curso de Inverno do Curso de Especialização em Direito da

Administração Pública (CEDAP/UFF). É pesquisador no Grupo de Pesquisa "Direitos

Fundamentais" e no de "Jurisdição Constitucional" da Universidade Federal Fluminense (UFF).E-mail:emersonacmoura@yahoo.com.br
\end{abstract}

Recebido em: 03/02/2017 Aprovado em: 25/10/2017

RESUMO: O conteúdo do princípio da autonomia da vontade, enquanto princípio basilar do regime jurídico de Direito Privado e, portanto, das relações jurídicas entre particulares, dentro de um Estado Democrático de Direito com epicentro na promoção dos direitos fundamentais e no princípio fundamental da dignidade da pessoa humana é o tema posto em debate. Analisa-se a partir do papel assumido pelos direitos fundamentais na ordem jurídica vigente, da sua irradiação no âmbito do direito infraconstitucional com a repersonalização do regime privado e o conteúdo da autonomia de vontade à luz do princípio fundamental da dignidade da pessoa humana, determinar em que medida o exercício da liberdade de dispor sobre a imagem e a intimidade nos reality shows, no que tange a atividades vexatórias, constitui ou não, violação ao reconhecimento da pessoa como um fim em si mesmo e demanda intervenção estatal.

Palavras-Chave:Direitos Fundamentais; Constitucionalização; Autonomia de Vontade; Direito de Comunicação; Reality Show.

ABSTRACT: The content of the principle of autonomy of the will, as a basic principle of the legal regime of private law and, therefore, of legal relations between individuals, within a Democratic State of Law with epicenter in the promotion of fundamental rights and in the fundamental principle of dignity of the human person is the subject of debate. It is analyzed from the role assumed by the fundamental rights in the current legal order, its radiance in the scope of infraconstitutional law with the repersonalization of the private regime and the content of the autonomy of will in the light of the fundamental principle of the dignity of the human person, determine in That the exercise of the freedom to dispose of the image and the intimacy in reality shows, in what concerns to vexatious activities, constitutes or not, violation to the recognition of the person as an end in itself and demands state intervention. 
Keywords: Fundamental Rights; Constitutionalisation; Autonomy of Will; Right Of Comunication; Reality show.

SUMÁRIO: I. Introdução II. Os Direitos Fundamentais e o Estado Democrático de Direito III. A Constitucionalização do Direito e a Repersonalização do Direito Civil IV. A Autonomia de Vontade e o Direito de Programação à Luz da Dignidade da Pessoa Humana V. Conclusão Referências

\section{INTRODUÇÃO}

Na mídia brasileira, os reality shows surgem a partir do ano de 2000, com o programa chamado "No Limite", havendo desde então a explosão dos programas baseado na vida real, com mais de 86 produções nacionais do gênero, que é marcado pela superexposição da vida dos participantes, através de sua autorização, bem como, com a realização de tarefas e provas para obtenção de itens e gêneros, alguns, inclusive, essenciais à própria existência.

Usualmente aponta-se a legalidade de tais provas vexatórias uma vez que seria originário de ato de disposição individual enquanto no exercício da liberdade contratual decorrente da autonomia de vontade embora envolva a questão mais do que apenas tais institutos já que versa a rigor sobre direitos fundamentais que não se sujeitam a rigor à disposição onerosa ou gratuita.

Busca o presente artigo verificar a abrangência do princípio da autonomia da vontade, enquanto princípio basilar do regime jurídico de Direito Privado e, portanto, das relações jurídicas entre particulares, dentro de um Estado Democrático de Direito com epicentro na promoção dos direitos fundamentais e no princípio fundamental da dignidade da pessoa humana.

Pretende, portanto, verificar como há uma tensão entre tais princípios a aplicação da técnica de ponderação de interesses, a ser realizada nos espaços legítimos democráticos, de conformação legislativa pelo Poder Legiferante que disciplina normativamente a matéria e da discricionariedade administrativa pelo Poder Executivo ao regular a atuação dos sujeitos envolvidos.

Adota-se como hipótese preliminar, sem embargo no reconhecimento da liberdade de manifestação de pensamento, criação, expressão e informação de veículo de comunicação social, de que a vedação a censura política, ideológica ou de qualquer natureza não importa em conteúdo irrestrito, mas se sujeita ao atendimento pelo exercício do direito de programação à regulação estatal das mídias e aos princípios que se sujeita as emissoras de rádio e de televisão.

Uma vez que há confluência entre distintos direitos fundamentais, como o direito de liberdade do participante que tem a autonomia para autodeterminar-se acerca da disposição sobre a sua imagem e de seus atos de intimidade e o direito de programação do canal midiático de exercer a expressão dentro dos limites admitidos pelo Direito inegável que traduz o objeto dessa investigação em um típico hard case.

Para tanto, adota-se para abordagem do objeto, a partir de um método dialético com esteio na doutrina pátria e estrangeira, bem como, na legislação e na jurisprudência quando pertinente, uma divisão do trabalho em três partes permitindo responder questões de ordem para análise da referida questão.

Primeiramente, deve-se verificar qual o papel assumido pelos direitos fundamentais na ordem jurídica vigente, de forma a delimitar em que medida os poderes públicos e os particulares encontram-se ou não vinculados ao seu respeito e/ou a sua concretização, extraindo a esfera, portanto, de limitação da ação estatal e autonomia individual em face de tais direitos.

Após, busca-se analisar de que forma os direitos fundamentais passam a redimensionar as relações privada, verificando através do fenômeno de constitucionalização do Direito, em que 
medida, o regime jurídico-privado, antes centrado na autonomia de vontade e patrimonialização das relações individuais, enfrenta um fenômeno de repersonalização, voltando-se a centralidade do homem e a funcionalização social dos seus direitos.

Por fim, pretende-se correlacionar o princípio da autonomia de vontade à luz do princípio fundamental da dignidade da pessoa humana, de modo a verificar, em que medida o exercício da liberdade de dispor sobre a imagem e a intimidade nos reality shows, no que tange a atividades vexatórias, constitui ou não, violação ao reconhecimento da pessoa como um fim em si mesmo e demanda intervenção estatal.

\section{OS DIREITOS FUNDAMENTAIS E O ESTADO DEMOCRÁTICO DE DIREITO}

Embora os direitos fundamentais, tenham antecedentes históricos na doutrina estóica greco-romana e cristã da Antiguidade ${ }^{1}$ e desenvolvimento nas doutrinas jusnaturalistas ${ }^{2}$ e previsão de direitos estamentais na Idade Média $^{3}$ a sua consagração ocorre apenas com o constitucionalismo na Idade Moderna, pelo reconhecimento nas principais Cartas e Constituições ${ }^{4}$.

No Estado Moderno, a evolução dos direitos fundamentais se liga ao processo histórico de reinvindicações sociais e contrastes de regimes políticos, bem como, o processo de desenvolvimento econômico, científico e político, que resulta em um primeiro momento na tensão dialética e harmonização entre liberdade e igualdade, direitos individuais e direitos sociais ${ }^{5}$.

Inicialmente, abrangiam os direitos individuais em razão do pensamento liberal-burguês e da doutrina iluminista e jusnaturalista do século XVII e XVIII, que se identificavam com os direitos negativos e marcavam a esfera de autonomia do indivíduo em face do poder estatal no exercício precípuo das liberdades ${ }^{6}$.

Porém, com a ascensão dos problemas sociais e econômicos no limiar do século XIX, os direitos fundamentais foram ampliados para incluir os direitos econômicos, sociais e culturais, que se correlacionando com os direitos positivos, passaram a impor ao Estado atuações capazes de promover a justiça e bem-estar social, na tutela do princípio da igualdade ${ }^{7}$.

Não obstante, naquela quadra histórica, já houvesse o reconhecimento pelos Estados dos direitos fundamentais em sua dúplice dimensão, a concepção da Constituição como documento

\footnotetext{
${ }^{1}$ Sobre o tema, vide: CARVELLI, Urbano. SCHOOL, Sandra. Evolução Histórica dos Direitos Fundamentais: Da Antiguidade até as Primeiras Importantes Declarações Nacionais de Direito.Revista de Informação Legislativa, Brasília, a. 48 n. 191 p. 169-171 jul/set 2011.

${ }^{2}$ LUÑO, Antonio Enrique Perez. Los Derechos Fundamentales. Madrid: Tecnos, 2004. p. 29-33.

${ }^{3}$ Tanto a sempre citada a Magna Charta Libertatum, firmada em 1215 pelo Rei João Sem-terra, as cartas de franquia e os forais outorgados pelos reis e portugueses e espanhóis no século XII e XIII, bem como, a Bula de Ouro da Hungria firmada por Afonso IX em 111, o Privilegio General outorgado por Pedro III em 1283 e os Privilégios da União Aragonesa em 1286 veiculavam prerrogativas ou privilégios aos estamentos sociais (Nobreza, Igreja, Corporações), que não correspondiam a direitos fundamentais, mas obrigações concretas daqueles reis que o subscreviam. ANDRADE, José Carlos Vieira de.Direitos Fundamentais na Contituição de 1976.Coimbra: Almedina, 2001. p. 25

${ }^{4}$ Com as declarações inglesas de direito - Petition Of Rights de 1628, Habeas Corpus Act de 1679, Bill Of Rights de 1689 - foram reconhediso direitos e liberdades aos cidadãos ingleses, como a legalidade, a proibição de prisões arbitrárias e o habeas corpus, que significa a transposição das liberdades estamentais para as liberdades gerais no plano de direito público. Com a Declaração americana de Direitos do Povo da Virgínia de 1776 e a Declaração francesa dos Direitos do Homem e do Cidadão de 1789 se marca a transição dos drieitos de liberdade legais ingleses para os direitos fundamentais constitucionais. SARLET, Ingo Wolfgang.Op. cit. p. 42-43.

${ }^{5}$ MIRANDA, Jorge. Os Direitos Fundamentais....Op. cit. p. 199.

${ }^{6}$ LUÑO, Antonio Enrique Perez. Op. cit. p. 38.

${ }^{7}$ BONAVIDES, Paulo. Do Estado Liberal ao Estado Social. 8 ed. São Paulo: Malheiros, 2007. p. 186.
} 
político que podia não ser cumprido pelos poderes públicos ${ }^{8}$ e a aceitação apenas da dimensão subjetiva dos direitos fundamentais, limitava a sua eficácia pelo Estado e particulares ${ }^{9}$.

Porém, observa-se com o término da segunda guerra mundial na Europa e o advento do processo de redemocratização do Brasil, uma série de transformações na forma de organização política e jurídica estatal, que marcam o advento do Estado Democrático de Direito e a ascensão dos pilares fundamentais do constitucionalismo contemporâneo ${ }^{10}$.

Com o reconhecimento da força normativa da Constituição ${ }^{11}$, substitui-se a concepção da lei fundamental como carta política com a atribuição do status de norma jurídica, que dotada de observação obrigatória, impõe no exercício do poder pelo Estado, limites e deveres de atuação, em especial, na tutela dos direitos fundamentais ${ }^{12}$.

Com o processo de incorporação de amplo elenco de direitos fundamentais aos textos constitucionais, bem como, a expansão da jurisdição constitucional, mediante a ampliação do elenco de legitimados para a propositura das ações e a criação de novos instrumentos de controle concentrado, garante-se a proteção dos direitos fundamentais do processo político majoritário ${ }^{13}$.

$\mathrm{Na}$ nossa experiência constitucional antes restrita a Constituições garantistas que tutelavam os direitos fundamentais como repositórios de promessas vagas ${ }^{14}$ o fenômeno ocorre com a promulgação da Constituição de 1988 voltada à promoção social e a crescente preocupação doutrinária com a aplicabilidade direta e imediata de seus preceitos ${ }^{15}$.

Com a constituição cidadã se ampliou o rol de direitos fundamentais, atribuindo significado ímpar aos mesmos, uma vez que os reconheceu como elementos integrantes de identidade e continuidade da lei fundamental, razão pelo qual, vedou qualquer reforma constitucional tendente a suprimi-los.

Interrompeu-se, portanto, o ciclo inicial de baixa normatividade das disposições que veiculavam os direitos fundamentais, em especial, das normas que declaravam os direitos sociais,

\footnotetext{
${ }^{8}$ Um dos trabalhos expoentes deste entendimento é Que é uma Constituição?de Ferdinand Lassalle, que considera que a Constituição só tem eficácia quando coincidir com os fatores do poder que regem o país. Caso contrário é apenas folha de papel que pode sucumbir por aquelas forças vitais que não iram aplicá-la. LASSALLE, Ferdinand. Que é uma Constituição. São Paulo: Edições e Publicações Brasil, 1933. p. 62

${ }^{9}$ DALlARI, Dalmo de Abreu. Estado de Direito e Direitos Fundamentais.In: AMLEIDA FILHO, Agassiz de. CRUZ, Danielle da Rocha (Coord). Estado de direito e direitos fundamentais: homenagem ao jurista Mário Moacyr Porto. Rio de Janeiro: Forense, 2005. p. 171.

${ }^{10}$ Como marco normativo, tem-se a promulgação da Lei Fundamental de Bonn na Alemanha e a Constituição da Itália, e a posterior, das cartas fundamentais de Portugal e Espanha. Alcança o fenômeno para além do velho continente, encontrando no Brasil com o fim da ditadura militar e a edição da Constituição da República, o ambiente propício para a garantia da estabilidade instituconal e da aplicabilidade das normas constitucionais. Sobre o tema: CARBONELL, Miguel. Nuevos Tiempos para el Constitucionalismo.In: CARBONELL, Miguel (Org). Neoconstitucionalismo(s). 1 ed. Madrid: Editorial Trotta, 2003. p. 9.

${ }^{11}$ HESSE, Konrad. A força normativa da Constituição. Porto Alegre: Sergio Antonio Fabris, 1991. p. 14-15.

12 Sobre as transformações do direito constitucional contemporâneo, consulte-se por todos: BARROSO, Luís Roberto.Neoconstitucionalismo e constitucionalização do direito: $O$ triunfo tardio do direito constitucional no Brasil. In: SOUZA NETO, Cláudio Pereira de; SARMENTO, Daniel (orgs.). A constitucionalização do direito: fundamentos teóricos e aplicações específicas. Rio de Janeiro: Lumen Juris, 2007. p. 203-250. Para uma análise crítica vide: SARMENTO, Daniel. O neoconstitucionalismo no Brasil: Riscos e possibilidades. In: (org.).

Filosofia e teoria constitucional contemporânea.Rio de Janeiro: Lumen Juris, 2009. p. 113-146.

${ }^{13}$ COELHO, Rosa Júlia Plá. Mecanismos de Proteção dos Direitos Fundamentais. 1 ed. Brasília: Ordem dos Advogados do Brasil, 2005. p. 34.

${ }^{14}$ BARROSO, Luís Roberto. O direito constitucional e a efetividade de suas normas. Limites e possibilidades da Constituição brasileira.7. ed. Rio de Janeiro: Renovar, 2003. p. 61.

${ }^{15}$ Embora a Constituição de 1988 seja o resultado de forças políticas antagônicas materializando uma constante tensão entre a ideologia liberal e a perspectiva social, denota-se um grande avanço na disciplina dos direitos sociais em relação às Constituições anteriores. Para uma visão geral sobre a evolução histórica, vide: TORRES, Marcelo Nóbrega da Câmara. Direitos sociais. Brasília: Senado Federal, 1987.
}

Revista de Direito Brasileira | São Paulo, SP | v. 20 | n. 8 | p. 272-286 |Mai./Ago. 2018 
antes remetidas à esfera programática de meras linhas diretoras aos poderes públicos e, tidas como dotadas de eficácia limitada ${ }^{16}$.

Por outro lado, houve também, o reconhecimento além de uma dimensão subjetiva dos direitos fundamentais - de proteção de situações individuais em face do poder público e dos particulares - de uma objetiva - de consagração de uma ordem objetiva de valores essenciais à sociedade $^{17}$, que projetam a unidade da Constituição e a congruência dos seus preceitos.

Por efeito, os direitos fundamentais enquanto objetivamente considerados passaram a impor normas de competência negativa, retirando da esfera de ação exclusiva dos poderes públicos, funcionam como critério de interpretação do direito infraconstitucional, que devem se adequar as suas prescrições, bem como, impõe deveres de tutela ao ente estatal.

Com esse novo status adquirido, os direitos fundamentais passaram a assumir, também, a posição de centralidade no sistema jurídico, instituindo uma ordem objetiva de valores que irradia sua força normativa pelo ordenamento, condicionando a interpretação das normas e institutos do Direito e vinculando a atuação dos poderes públicos ${ }^{18}$.

Também, passam a corresponder ao lado dos princípios estruturais e organizacionais um núcleo básico do ordenamento constitucional ${ }^{19}$ e critério de interpretação de suas normas, categorias e institutos, em um fenômeno de abertura constitucional ou de constitucionalização em aberto, que importa na irradiação ou expansão da dignidade e dos direitos do homem ${ }^{20}$.

O Estado Democrático de Direito passa ser caracterizado por uma abertura constitucional radicado no extenso catálogo de direitos fundamentais - civis, políticos, econômicos, sociais e culturais - que com epicentro no princípio da dignidade da pessoa humana alcança a superação da tradicional divisão de domínio e papéis do Estado e da sociedade civil ${ }^{21}$.

Ademais, transforma-se também, como um dos critérios de verificação da legitimidade do Estado, que passa a ser medido pelo grau de observância e de implementação dos direitos fundamentais radicados da dignidade da pessoa humana pelos poderes públicos de forma direta ou através da atuação de terceiros ${ }^{22}$.

A própria concepção dos direitos fundamentais, passa a determinar o significado dos poderes públicos, uma vez que, há uma íntima relação entre o papel assumido por esses direitos públicos subjetivos e a organização e exercício das funções estatais, uma vez que garantem que o sistema político e jurídico se orientará pelo respeito e promoção da pessoa humana ${ }^{23}$.

Por efeito, o reconhecimento normativo dos direitos fundamentais e o papel assumido pelo seu sistema no Estado Democrático de Direito, reorienta a relação da pessoa com os poderes públicos, redimensionando a atuação privada ao respeito e concretização tanto dos preceitos fundamentais, quanto da dignidade da pessoa humana.

\footnotetext{
${ }^{16}$ SILVA, José Afonso da.Aplicabilidade das normas constitucionais. 7. ed. São Paulo: Malheiros, 2008. p. 140142.

${ }^{17}$ Liga-se a dimensão objetiva a compreensão de que os direitos fundamentais consagram os valores mais importantes da comunidade política potencializando a sua irradiação para todos os campos do Direito, e sua eficácia enquanto fins ou valores comunitários sobre uma miríade de relações jurídicas. SARMENTO, Daniel. Direitos Fundamentais e Relações Privadas. Rio de Janeiro: Lumen Juris, 2004. p. 371.

${ }^{18}$ Apresentam os direitos fundamentais, portanto, uma dupla ordem de sentido: como vínculos axiológicos, que condicionam a validade material das normas produzidas e enquanto fins que orientam o Estado Constitucional de Direito. FERRAJOLI, Luigi. Derechos e Garantias: La ley del mais débil. 1 ed. Madrid: Trotta, 1999. p. 22.

${ }^{19}$ Os direitos fundamentais integram a substância propriamente dita da Constituição formado pelas decisões fundamentais da ordem normativa.SARLET, Ingo Wolfgang.Op. cit. p. 61.

${ }^{20} \mathrm{E}$ alçado em forja central da eclética e difusão produção de valores e princípios encarecidos pela sociedade contemporânea. CASTRO, Carlos Roberto Siqueira.CASTRO, Carlos Roberto Siqueira. A Constituição Aberta e os Direitos Fundamentais: ensaios sobre o constitucionalismo pós-moderno e comunitário. Rio de Janeiro: Forense, 2010. p. 20-21.

${ }^{21}$ CASTRO, Carlos Roberto Siqueira.Op. cit. p. 15-19.

${ }^{22}$ DALLARI, Dalmo de Abreu. Op. cit. p. 182-183.

${ }^{23}$ LUÑO, Antonio Enrique Perez. Op. cit. p. 20.
}

Revista de Direito Brasileira | São Paulo, SP | v. 20 | n. 8 | p. 272-286 |Mai./Ago. 2018 
O tema será tratado a seguir.

\section{A CONSTITUCIONALIZAÇÃO DO DIREITO E A REPERSONALIZAÇÃO DO DIREITO CIVIL}

Com o reconhecimento da supremacia axiológica da Constituição e do novo status dos direitos fundamentais na ordem jurídica, deriva um processo de apreensão do sistema sob a ótica da Constituição com o objetivo de realizar os bens e valores fundamentais veiculados, em um processo designado de constitucionalização do Direito ${ }^{24}$.

Corresponde o fenômeno, portanto, à transformação do ordenamento jurídico oriundo de sua impregnação pelas normas constitucionais, que passam a redimensionar as atividades legislativa, judicial e doutrinária ao novo papel de centralidade assumido pela Constituição nas relações com os poderes públicos e com a sociedade.

No âmbito da legislação, abrange a limitação do espaço de conformação do Poder Legislativo, subtraindo de sua esfera de liberdade a definição dos bens e interesses a serem perseguidos, reservando a este precipuamente a eleição dos meios necessários a concretização dos fins e objetivos almejados pela sociedade e veiculados pela Constituição ${ }^{25}$.

No campo da jurisprudência, envolve a ampliação da competência do Poder Judiciário oriunda do poder-dever de aplicar os preceitos constitucionais, que importa na possibilidade de invalidação dos atos emanados pelos poderes públicos ou originários dos particulares através da interpretação criativa das normas jurídicas à luz da Constituição ${ }^{26}$.

No espaço da doutrina, inclui a releitura dos preceitos e institutos dos distintos ramos jurídicos com a recondução dos seus fundamentos axiológicos às normas constitucionais e o alinhamento do seu conteúdo normativo como revelação dos preceitos fundamentais veiculados pela Constituição garantindo a superioridade de suas normas e a realização dos valores da sociedade. $^{27}$

Embora a constitucionalização do Direito decorra principalmente do reconhecimento da força vinculante dos preceitos constitucionais e do papel de centralidade dos direitos fundamentais na ordem jurídica, para que se opere a completa impregnação da ordem jurídica pelas normas constitucionais, torna-se necessário o preenchimento de outras condições necessárias ${ }^{28}$.

De início, impõe-se a existência de uma constituição rígida aferida através da definição de um procedimento de modificação das normas constitucionais distinto do processo ordinário de formação das leis, que garanta a distinção de níveis hierárquicos normativos na ordem jurídica e a preeminência dos preceitos constitucionais sobre as demais normas jurídicas ${ }^{29}$.

Neste tocante, demonstra-se essencial a criação de um mecanismo de garantia da Constituição capaz de preservar a hierarquia de seus preceitos exteriorizado na previsão de um ou

\footnotetext{
${ }^{24}$ SAMPAIO, José Adércio Leite. Mito e História da Constituição: Prenúncios Sobre a Constitucionalização do Direito.In: SOUZA NETO, Cláudio Pereira e SARMENTO, Daniel. SARMENTO, Daniel e SOUZA NETO, Cláudio Pereira de (Orgs).A Constitucionalização do Direito: Fundamentos Teóricos e Aplicações Específicas. Rio de Janeiro: Lumen Juris, 2007. p. 200.

${ }^{25}$ FERRAJOLI, Luigi. Ob. cit. p. 18-19.

${ }^{26}$ SANCHÍS, Luis Prietro. Sobre el Neoconstitucionalismo y Sus Implicaciones in: Justicia Constitucional y Derechos Fundamentales. Madrid: Trotta, 2003.p. 129-131.

${ }^{27}$ ZAGREBELSKY, G.El Derecho Dúctil: ley, derechos y justicia. 4 ed. Madrid: Editorial Trotta, 2002. p. 14 e 39-40.

${ }^{28}$ Adota-se o modelo proposto por Riccardo Guastini onde são consideradas determinadas condições para que um ordenamento jurídico possa ser considerado completamente impregnado pelas normas constitucionais. GUASTINI, Riccardo. La Constitucionalizacion Del Ordenamiento Juridicoin: CARBONELL, Miguel (Coord.) Neoconstitucionalismo(s)...Ob. cit. p. 50-56.

${ }^{29}$ VIEIRA, Oscar Vilhena. A Constituição e sua Reserva de Justiça: Um Ensaio Sobre Os Limites Materiais Ao Poder de Reforma.São Paulo: Malheiros, 1999.
} 
mais órgãos políticos ou judiciais incumbidos de exercer o controle de conformidade das leis e atos normativos emanados pelos poderes públicos às normas constitucionais ${ }^{30}$.

Envolve, ainda, a compreensão de que toda decisão legislativa é pré-disciplinada por normas constitucionais, idôneas, portanto, a regular de forma explícita ou implícita qualquer aspecto da vida política e social. Isto importa no reconhecimento da inexistência de qualquer questão que não esteja sujeita ao controle de parametricidade com a Constituição ${ }^{31}$.

$\mathrm{Na}$ hermenêutica constitucional, abrange o emprego da técnica de eleição dentre as distintas formas de interpretação aquela capaz de harmonizar o conteúdo da lei com a Constituição, de modo a preservar o princípio majoritário, evitando sua contrariedade com as normas constitucionais e garantindo a manutenção da validade da $1 \mathrm{ei}^{32}$.

Por fim, inclui a influência da Constituição sobre as relações políticas, aferida através da atribuição aos órgãos de controle de constitucionalidade da resolução de conflitos de competência relativo ao exercício do poder estatal, do controle do exercício da discricionariedade legislativa pelo Poder Judiciário e do emprego das normas constitucionais na argumentação dos atores políticos $^{33}$.

$\mathrm{Na}$ nossa ordem jurídica, o fenômeno de constitucionalização inicia-se com a promulgação da Constituição da República de 1988, em um processo que resultou no seu deslocamento para o eixo central do sistema jurídico e reconhecimento da sua supremacia axiológica, potencializada pela erradicação daqueles fatores mencionados.

A previsão exaustiva dos bens e interesses sociais na lei fundamental produziu a subtração de distintas questões da vida política e social do alcance do legislador, que passaram a encontrar fundamentos imediatos nas normas constitucionais sujeitando-se, portanto, ao controle de adequabilidade com a lei fundamental. ${ }^{34}$

Neste ponto, a expansão da jurisdição constitucional, mediante a criação de novos mecanismos de controle de constitucionalidade e ampliação do elenco de legitimados ativos para a propositura das ações abstratas, garantiu a proteção das normas constitucionais e a preservação de sua hierarquia mediante atuação pelo Poder Judiciário ${ }^{35}$.

Por efeito, a ampliação da competência do Poder Judiciário para o controle de constitucionalidade dos atos emanados pelos poderes públicos e o crescente exercício das ações

\footnotetext{
${ }^{30}$ Dentre os variados sistemas de controle de constitucionalidade, destaca-se o modelo francês de controle concentrado e preventivo exercido por órgão político e americano de controle abstrato e preventivo exercido por órgão judicial. O modelo brasileiro é eclético adotando todas as espécies e modalidades admitidas no Direito Comparado. Sobre o tema vide: CAPPELLETTI, Mauro. O Controle Judicial de Constitucionalidade das Leis no Direito Comparado. 1 ed. Porto Alegre: Sergio Antonio Fabris, 1984.

${ }^{31}$ Isto não significa desconsiderar que existem questões de natureza política sujeitas ao princípio majoritário, porém, compreender que existem outros princípios a serem preservados na ordem constitucional. Compete ao Poder Judiciário, portanto, resguardar o processo democrático e promover os valores fundamentais constitucionais, assim como assegurar a liberdade institucional. BARROSO, Luís Roberto. Dez Anos da Constituição Brasileira de 1988. Revista de Direito Administrativo $\mathrm{n}^{\circ} 214$.

${ }^{32}$ MENDES, Gilmar Ferreira. Controle de Constitucionalidade na Alemanha: A Declaração de Nulidade da Lei Inconstitucional, a Interpretação Conforme à Constituição e a Declaração de Constitucionalidade da Lei na Jurisprudência da Corte Constitucional Alemãin: Revista de Direito Administrativo, nº 193, 1993 p. $22-27$.

33 Sobre o tema: SARMENTO, Daniel. O Neoconstitucionalismo no Brasil: Riscos e Possibilidades in: SARMENTO, Daniel (Coord). Filosofia e Teoria Constitucional Contemporânea. Rio de Janeiro: Lumen Juris, 2009. p. 133-139.

${ }^{34}$ A hospedagem no texto constitucional de inúmeros princípios vagos, inclusive, alguns de duvidosa dignidade constitucional, dotados de forte carga axiológica e poder de irradiação, favoreceram o processo de constitucionalização do Direito. SARMENTO, Daniel. O Neoconstitucionalismo...Ob cit. p. 125.

${ }^{35}$ Amplia-se o objeto e escopo da jurisdição constitucional através da ampliação do elenco de legitimados ativos para a propositura da ação direta de inconstitucionalidade (artigo 103 inciso I a IX), da criação do controle de

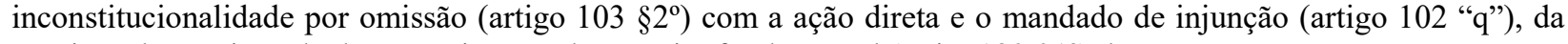
previsão da arguição de descumprimento de preceito fundamental (artigo102 $\S 1^{\circ}$ ) dentre outros.
} 
abstratas pelos atores políticos e sociais, permitiu um processo de judicialização da política, que amplia a influência da Constituição sobre as relações políticas ${ }^{36}$.

A necessidade de reelaboração doutrinária da hermenêutica constitucional de forma a resguardar o processo democrático e a estabilidade institucional na promoção dos valores fundamentais, conduzindo à interpretação da lei conforme a Constituição quando possível evitando a contrariedade com os seus preceitos e garantindo a manutenção da validade da lei ${ }^{37}$.

Embora o processo de constitucionalização tenha permeado os distintos ramos do ordenamento jurídico, promovendo o realinhamento dos preceitos e institutos às normas constitucionais, o fenômeno tem alcançado especial relevo na órbita de três grandes domínios infraconstitucionais, ao qual se sucede a análise: o direito civil, penal e administrativo.

$\mathrm{Na}$ órbita civil, observa-se um deslocamento do Código Civil da posição central antes ocupada no sistema jurídico, com a submissão de suas normas e institutos a um redimensionamento axiológico a partir da Constituição e a respectiva imposição de um novo complexo de valores e princípios que passam a reger a interpretação do direito civil.

Assume a Constituição o papel integrador da ordem jurídica, mediante a liderança axiológica em face dos microssistemas normativos que passam a ser associados aos valores e princípios constitucionais, como a função social da propriedade, a nova configuração da família baseada na igualdade entre os cônjuges e filhos e na pluralidade de sua constituição, dentre outros $^{38}$.

Em um vértice, destaca-se a irradiação do princípio da dignidade da pessoa humana sobre as relações privadas, promovendo uma despatrimonialização e repersonalização do direito civil, com o reconhecimento da centralidade do homem e o desenvolvimento dos seus direitos de personalidade e, por efeito, a preeminência da tutela da pessoa nas relações jurídicas patrimoniais.

Sob outro ângulo, engloba a aplicabilidade dos direitos fundamentais às relações privadas, que na vertente dominante, importa no reconhecimento de que as referidas normas constitucionais se aplicam com eficácia direta e imediata, mediante a ponderação entre o princípio da livre iniciativa e autonomia de vontade e o direito fundamental em jogo ${ }^{39^{3}}$.

Por efeito, o reconhecimento normativo dos direitos fundamentais e o papel assumido pelo seu sistema no Estado Democrático de Direito, reorienta a relação da pessoa com os poderes públicos, redimensionando a atuação privada ao respeito e concretização dos preceitos fundamentais e da dignidade da pessoa humana.

O tema será tratado a seguir.

\footnotetext{
${ }^{36}$ Como ilustrações têm-se as decisões do Supremo Tribunal Federal quanto aos limites de investigação das Comissões Parlamentares, a fidelidade partidária, a Reforma da Previdência e a Reforma do Judiciário. Quanto aos direitos fundamentais têm-se a interrupção da gestação de fetos inviáveis, as pesquisas com células-troncos embrionárias e as políticas públicas de distribuição de medicamentos.

37 Compete ao Poder Judiciário preservar as condições essenciais de funcionamento do Estado Democrático mediante a tutela dos princípios fundamentais e procedimentos adequados à participação e deliberação, Sobre o tema: SOUZA NETO, Cláudio pereira. Jurisdição, Democracia e Racionalidade Prática. Rio de Janeiro: Renovar, 2002.

${ }^{38}$ CASTRO, Carlos Roberto Siqueira. A Constituição Aberta e os Direitos Fundamentais: Ensaio Sobre o Constitucionalismo Pós-Moderno e Comunitário. Rio de Janeiro: Forense, 2005. p. 16.

${ }^{39}$ Não se ignora, todavia, a existência da doutrina americana da state action que nega baseada na autonomia privada e no pacto federativo a eficácia dos direitos fundamentais nas relações privadas, bem como, no direito pátrio a teoria da eficácia indireta e imediata dos direitos fundamentais na esfera privada, que apenas reconhece a irradiação dos direitos fundamentais na interpretação das normas. Sobre o tema: SARMENTO, Daniel. Direitos Fundamentais e Relações Privadas. Rio de Janeiro: Lumen Juris, 2004.
} 


\section{A AUTONOMIA dE VONTADE E O DIREITO DE PROGRAMAÇÃO À LUZ DA DIGNIDADE DA PESSOA HUMANA}

Com o processo de constitucionalização do Direito, o princípio ético-jurídico da dignidade da pessoa humana passa a atribuir a unidade valorativa e sistemática ao Direito Civil, regulamentando a autonomia de vontade em prol da solidariedade social, de forma a possibilitar que ocorra o livre desenvolvimento da personalidade de cada um dos membros da comunidade. ${ }^{40}$

Abrange, portanto, não apenas o respeito e proteção da integridade física e psíquica em da pessoa humana, mas a liberdade pessoal e os seus desdobramentos, de maneira a abranger o reconhecimento e proteção à identidade pessoal, que exige o respeito à privacidade, intimidade, honra e imagem, bem como, todas as outras dimensões umbilicalmente vinculadas à dignidade da pessoa humana. ${ }^{41}$

Por efeito, ainda que haja renúncia ${ }^{42}$ ou auto-restrição do direito fundamental por seu titular, no exercício de sua liberdade negocial não viciada - com igualdade de sujeitos e existência de uma vontade livre e esclarecida - isto não pode gerar exclusão da proteção dada pelas normas constitucionais, se atingir aquele mínimo de conteúdo do direito para além do qual o indivíduo se reduz à condição de objeto e não pessoa. ${ }^{43}$

É o reconhecimento que embora os direitos fundamentais se sujeitam a limitações e ainda que se admita a relativização e eventual restrição do princípio da dignidade da pessoa humana, que isto não importe o seu núcleo intangível, que pode ser delimitado como na vedação de qualquer conduta que importe em coisificação ou em qualquer forma em uma instrumentalização do ser humano. ${ }^{44}$

Isto porque, a prática de atos indignos, embora não acarrete a perda da dignidade do seu titular, acaba por colocar quem os pratica numa condição de desigualdade na sua relação com os seus semelhantes, de maneira que sua relativização ainda que em face de outros valores sociais, só pode ocorrer quando o intuito for o de salvaguardar a vida e a dignidade pessoal dos demais integrantes de determinada comunidade. ${ }^{45}$

O Conselho de Estado Francês já se manifestou sobre a matéria no conhecido caso Commune de Morsang-sur-Orge v. Socit Fun Produção et M. Wackenheim, onde a Administração Local, no uso do poder de polícia, restringiu através de decreto a proibição do espetáculo "lancer de nains" sob alegação da violação da ordem pública e da dignidade da pessoa humana.

Entendeu a corte que o uso de um ser humano, inclusive, afetado com deficiência física como projétil viola a sua dignidade humana se sobrepondo em tal violação sob a liberdade de trabalho, comércio e indústria, tendo o Estado cumprido o dever de garantir a ordem, segurança e

\footnotetext{
${ }^{40}$ MORAES, Maria Celina Bodin de.Constituição e Direito Civil: Tendências in: Revista dos Tribunais. Vol. 779 set. 2000 p. 55 e 59.

${ }^{41}$ SARLET, Ingo Wolfgang.As Dimensões da Dignidade da Pessoa Humana: Construindo uma compreensão jurídico-constitucional necessária e possível. Revista Brasileira de Direito Constitucional, n. 09 jan/jul 2007, p. 363.

${ }^{42}$ Adere-se ao entendimento da doutrina tradicional que os direitos fundamentais são justamente caracterizados pela inalienabilidade, imprescritibilidade e impossibilidade de renúncia.SILVA, José Afonso da.Curso de Direito Constitucional Positivo. 35. ed., rev. e atualizada até a emenda constitucional no 68. São Paulo: Malheiros, 2012, p. 91-95.

${ }^{43}$ ANDRADE, José Carlos Vieira. Os direitos, liberdades e garantias no âmbito das relações entre particulares. In: SARLET, Ingo Wolfgang (Org.). Constituição, Direitos Fundamentais e Direito Privado. $2^{\text {a }}$.ed. Porto Alegre: Livraria do Advogado, 2006. p. 296.

${ }^{44}$ SARLET, Ingo Wolfgang.Dignidade da pessoa humana e direitos fundamentais na Constituição Federal de 1988. Porto Alegre: Livraria do Advogado, 2001. p.138.

${ }^{45}$ SARLET, Ingo Wolfgang.Dignidade... Op. cit.p. 122 e 130.
}

Revista de Direito Brasileira | São Paulo, SP | v. 20 | n. 8 | p. 272-286 |Mai./Ago. 2018 
salubridade pública ao editar o decreto, impedindo, portanto, a utilização de uma pessoa como forma de entretenimento ou mera atração. ${ }^{46}$

Enseja, portanto, a adoção de medidas estatais capazes de impedir a veiculação de tais condutas, que atentem ainda com respaldo na autonomia de vontade no princípio da dignidade da pessoa humana, o que importará através da regulação normativa ou administrativa, na restrição do campo de autonomia da pessoa privada na utilização da liberdade de programação e de comunicação.

A liberdade de programação concede ao seu titular a possibilidade de conformação dos conteúdos a serem publicizados, de forma a atender diferentes públicos com interesses, valores e gostos distintos, o que impede a tentativa de imposição de constrições conceituais à mesma, o que conduz a rigor, a um campo que afasta todas as interferências estatais, na seleção e conformação dos conteúdos da programação. ${ }^{47}$

Isto não impede, todavia, que sejam determinadas atribuição de classificação ou adjetivação indicativa sobre o conteúdo dos programas, que tem por objetivo indicar as faixas etárias e os horários recomendados, o que não limita a informação ao telespectador e não determina a conduta das emissoras, já que a classificação não é cogente ou obrigatória, mas indicativa. $^{48}$

Tão pouco, que o exercício desta liberdade fundamental de programação será plena ou absoluta, mas como qualquer direito fundamental é relativo, se sujeitando à restrições determinadas pela própria ordem jurídica, de forma a compatibilizar o seu exercício com a proteção aos demais valores e bens essenciais da sociedade, esculpidos na Constituição Federal e legislação infraconstitucional.

Neste sentido, embora preserve a Constituição Federal, a livre manifestação do pensamento, a criação, a expressão e a informação, limita a obediência as próprias restrições trazidas pela lei fundamental ${ }^{49}$, determinando os princípios aplicáveis a produção e a programação das emissoras de rádio e televisão, dentre os quais, o respeito aos valores éticos e sociais da pessoa e da família. ${ }^{50}$

Note, porém, que as limitações infraconstitucionais - normativas ou administrativas sobre a comunicação social, como a programação independem de tais princípios, pois é possível na tutela dos bens jurídicos protegidos pela ordem constitucional e aos princípios regentes do serviço público e de atividades sob a regulação estatal, limitações normativas e/ou administrativas de conteúdo e forma à prestação de serviço de radiodifusão. ${ }^{51}$

No âmbito internacional, o Pacto de São José da Costa Rica prevê o direito à liberdade de pensamento e de expressão, que não pode estar sujeito à censura prévia, mas se limita as restrições fixadas em lei, para assegurar os interesses públicos - proteção da segurança nacional,

${ }^{46}$ FRANCE, Commune de Morsang-sur-Orge v. Société Fun Production et M. Wackenheim, n. 136727, Conseil
d'Etat, 27 octobre 1995, AJDA 1995 Jurisprudence p. 942. Disponível em: http://www.legifrance.gouv.fr/affichJuriAdmin.do?oldAction=rechJuriAdmin\&idTexte=CETATEXT000007877723 Acesso em 30.07.2017.

${ }^{47}$ CANOTILHO, J. J. Gomes; MACHADO, Jónatas."Reality Shows" e liberdade de programação. Coimbra: Coimbra Editora, 2003. p. 28-31.

${ }^{48}$ BARROSO, Luis Roberto. Liberdade de expressão, censura e controle da programação de televisão na Constituição de 1988. Revista dos Tribunais.São Paulo, ano 90, v. 790, p. 129-152, ago 2001. p. 147

${ }^{49}$ BRASIL, Constituição da República Federativa do Brasil de 05 de Outubro de 1988. Art. 220. "A manifestação do pensamento, a criação, a expressão e a informação, sob qualquer forma, processo ou veículo não sofrerão qualquer restrição, observado o disposto nesta Constituição".

${ }^{50}$ BRASIL, Constituição da República Federativa do Brasil de 05 de Outubro de 1988. Art. 221. A produção e a programação das emissoras de rádio e televisão atenderão aos seguintes princípios: I - preferência a finalidades educativas, artísticas, culturais e informativas; II - promoção da cultura nacional e regional e estímulo à produção independente que objetive sua divulgação; III - regionalização da produção cultural, artística e jornalística, conforme percentuais estabelecidos em lei; IV - respeito aos valores éticos e sociais da pessoa e da família.

${ }^{51}$ ARANHA, Márcio Iorio. 4414-4415. 
da ordem pública, ou da saúde ou da moral públicas - e os direitos fundamentais - o respeito aos direitos ou à reputação das demais pessoas ${ }^{52}$.

No Direito Comparado, inexiste disciplina constitucional acerca do exercício da comunicação social, havendo a previsão do direito à liberdade de manifestação e de imprensa ${ }^{53}$, sendo a regulação do exercício deste direito fundamental, quase que exclusivamente de natureza infraconstitucional, limitando o seu exercício de forma a garantir a pluralidade, o atendimento ao interesse público e outros vetores ${ }^{54}$.

Por efeito, tais enunciados principiológicos constitucionais não apenas possuem o efeito irradiador genérico voltado a informar a interpretação do ordenamento jurídico, mas tendem a resguardar a constitucionalidade de produção legal tendente ao condicionamento do conteúdo e forma de prestação de serviço de radiodifusão sonora e de sons e imagens afetos a bens jurídicos da ordem social constitucional ${ }^{55}$.

Constituem poder-dever do Poder Legislativo na regulação e da Administração Pública à configuração normativa e administrativa dos serviços de radiodifusão e de comunicação, de modo que a produção e a programação pertinentes se caracterizem pelo respeito aos princípios constitucionais da comunicação social, conformando a concessão, permissão ou autorização de serviços de radiodifusão ou de comunicação aos ditames constitucionais ${ }^{56}$.

Sob tal giro, o princípio que impõe o respeito aos valores éticos da pessoa e da família, corresponde à concretização da proteção do homem no âmbito do direito da programação ${ }^{57}$, de forma que a comunicação social no Estado Democrático de Direito Brasileiro deve ser expressão da pluralidade e da democracia, mas, também, atuar como a emanação da dignidade da pessoa humana $^{58}$.

O direito de programação, portanto, apenas pode ser tido como tutelado pela ordem jurídica, no atendimento aos princípios constitucionais que se sujeita, de forma que qualquer utilização com fins ao "o sadismo, ao voyeurismo ou à pura e simples grossura" não está abrangido pela proteção do ordenamento jurídico, que jamais protegeria pretensão avessa aos seus próprios ditames 59 .

\footnotetext{
${ }^{52}$ BRASIL, Decreto 678 de 06 de Novembro de 1992.Anexo. Art. 13 "1.Toda pessoa tem direito à liberdade de pensamento e de expressão. Esse direito compreende a liberdade de buscar, receber e difundir informações e ideias de toda natureza, sem consideração de fronteiras, verbalmente ou por escrito, ou em forma impressa ou artística, ou por qualquer outro processo de sua escolha. 2. O exercício do direito previsto no inciso precedente

não pode estar sujeito a censura prévia, mas a responsabilidades ulteriores, que devem ser expressamente fixadas pela lei a ser necessárias para assegurar: a) o respeito aos direitos ou à reputação das demais pessoas; ou b) a proteção da segurança nacional, da ordem pública, ou da saúde ou da moral públicas."

${ }_{53}$ Assim, é na Lei Fundamental alemã de Bonn (art. $5^{\circ}$ ), Constituição da Argentina (art. 14), do Chile (art. 12), dos Estados Unidos (Primeira Emenda), da Espanha (art. 20(3)), da França (Declaração Universal dos Direitos do Homem e do Cidadão, arts. 10 e 11 c/c o Preâmbulo da Constituição de 1958), da Itália (art. 21), do México (art. $6^{\circ}$ ), de Moçambique (art. 48), do Paraguai (art. 27, 29 e 31), do Peru (arts. 14 e 61), de Portugal (arts. 38 e 73(3)), do Uruguai (art. 29) e a Carta de Direitos e Liberdades da Lei Constitucional do Canadá (art. $2^{\circ}, b$ ).

${ }^{54}$ ARANHA, Márcio Iorio. 4423-4425.

${ }^{55}$ ARANHA, Márcio Iorio. 4423-4425.

${ }^{56}$ ARANHA, Márcio Iorio. 4426.

${ }^{57}$ MENDES, Gilmar Ferreira; BRANCO, Paulo Gustavo Gonet.Curso de Direito Constitucional. São Paulo: Saraiva, 2014. p. 265.

${ }^{58}$ BRASIL, Supremo Tribunal Federal, Arguição de Descumprimento de Preceito Fundamental no 130/DF: Ementa: "Arguição de Descumprimento de Preceito Fundamental (ADPF). Lei de Imprensa. Adequação da Ação. Regime Constitucional da "Liberdade de Informação Jornalística", Expressão Sinônima de Ação.Regime Constitucional da "Liberdade de Informação Jornalística", expressão sinônima de liberdade de imprensa. A "plena" liberdade de imprensa como categoria jurídica proibitiva de qualquer tipo de censura prévia. A plenitude da liberdade de imprensa como reforço ou sobretutela das liberdades de manifestação do pensamento, de informação e de expressão artística, científica, intelectual e comunicacional. Liberdades que dão conteúdo as relações de imprensa e que se põem como superiores bens de personalidade e mais direta emanação do princípio da dignidade da pessoa humana (...)"

${ }^{59}$ MOREIRA, Ação Civil Pública e Programação de TV. Revista de Direito Administrativo, 201. Rio de Janeiro, jul/set, 1995, p. 45-56.
}

Revista de Direito Brasileira | São Paulo, SP | v. 20 | n. 8 | p. 272-286 |Mai./Ago. 2018 
Corresponde a vetor as emissoras de rádio e televisão, que impõe o tratamento do sujeito com valor intrínseco e acima de todas as coisas, havendo desrespeito a redução a condição de objeto para satisfação de interesses, de forma que a exposição do ser humano como coisa motivadora da curiosidade de terceiros, como instrumento de divertimento, não é exercício legítimo da expressão, mas afronta a dignidade da pessoa humana ${ }^{60}$.

Por efeito, o exercício do direito de programação, no que tange aos programas reality shows, que possuam provas ou tarefas capaz de atentar contra a dignidade da pessoa humana, com tratamento que denote a instrumentalização do ser ou imponha qualquer tratamento degradante, deve ser objeto de regulação normativa ou administrativa, capaz de sanar com tal conduta, readequando o exercício da liberdade fundamental à ordem constitucional.

Neste sentido, houve um projeto de lei de $n^{\circ} 2.812 / 2011$ arquivado pelo autor ${ }^{61}$ que vedava a exposição de pessoas a situações e cenas em programas de reality show que pudessem ser caracterizadas contra a integridade física, psicológica e moral dos participantes, sob pena de sujeição as infrações previstas no Código Brasileiro de Telecomunicações ${ }^{62}$, além do pagamento de multa por infração cometida.

Em igual sentido, o projeto de lei de $n^{0} 6.446 / 2009$ também arquivado ${ }^{63}$, propugnava a imposição de sanções em razão de situações e cenas capazes de atentar contra a dignidade da pessoa humana. Atualmente, inexistem outros projetos em trâmite que regulem em específico, os programas de reality show, se submetendo, portanto, ao regime geral privatista de reparação civil.

No que tange as medidas administrativas, desconhece-se regulação sob o conteúdo dos programas de reality shows, de forma que persiste o uso de etapas e provas vexatórias, com a instrumentalidade do ser humano ao entretenimento, em abuso do direito de programação e exercício ilícito da autonomia de vontade, uma vez que atenta contra a dignidade da pessoa humana e ao princípio de respeito aos valores éticos da pessoa na comunicação social.

Corresponde a situação grave, pois uma vez que as sociedades contemporâneas são essencialmente midiáticas, sendo as relações sociais e políticas intermediadas pela mídia ${ }^{64}$, com a influência na formação e construções humanas é inexorável, que a existência de programas que atentem contra a dignidade da pessoa humana reiteram a cultura brasileira de desrespeito aos direitos fundamentais.

\section{CONCLUSÃO}

Traduz a Constituição Federal de 1988 um modelo de Estado Democrático de Direito marcado pela tensão imanente entre constitucionalismo e democracia exteriorizado no influxo da garantia do princípio majoritário e vontade das maiorias, mas igualmente, na proteção dos bens e valores constitucionais exteriorizado na tutela dos direitos fundamentais, em especial, das minorias.

Sob tal viés, o papel da jurisdição constitucional eminentemente contra majoritário pretende garantir a proteção dos direitos fundamentais na preservação dos valores e bens protegidos pelo constituinte originário, ainda que isto importe eventualmente em uma oposição à vontade das maiorias atuais, mesmo que exteriorizadas através de um constituinte reformador ou um legislador ordinário.

\footnotetext{
${ }^{60}$ MENDES, Gilmar Ferreira; BRANCO, Paulo Gustavo Gonet.Op. cit. p. 265.

${ }^{61}$ BRASIL, Projeto de Lei $\mathrm{n}^{\mathrm{o}} 2.812$ de 2011. Autor: Edson Pimenta Disponível em: http://www2.camara.leg.br/proposicoesWeb/prop_mostrarintegra;jsessionid=E20111A19279830A0B8A4B495BE6 A69C.proposicoesWeb1?codteor=945252\&filename=PL+2812/2011 Acesso em 25.10.2016.

${ }^{62}$ BRASIL, Lei Federal no 4.117 de 27 de Agosto de 1962.

${ }^{63}$ BRASIL, Projeto de Lei $\mathrm{n}^{\mathrm{o}} 6.446$ de 2009. Autor: Nelson Goetten. Disponível em: http://www2.camara.leg.br/proposicoesWeb/prop mostrarintegra?codteor $=715581 \&$ filename $=\mathrm{PL}+6446 / 2009$ Acesso em 25.10.2016.

${ }^{64}$ CASTELLS, Manuel. O poder da identidade. São Paulo: Paz e Terra, 2000. p. 368.

Revista de Direito Brasileira | São Paulo, SP | v. 20 | n. 8 | p. 272-286 |Mai./Ago. 2018
} 
Sob tal viés inegável que a ordem constitucional pretende proteger o princípio do pluralismo e o princípio democrático através da proteção das liberdades de agir conforme seu discernimento, de expressão de sua personalidade, de manifestação de seu pensamento e de comunicação para a coletividade, porém, isto não importe que o próprio constituinte não limitou tais direitos em evidente restrição constitucional.

Neste sentido, veda o anonimato nas manifestações, protege quanto ao dano moral e determina que o exercício da liberdade de comunicação esteja restrito por bens e valores tutelados constitucionalmente, em especial, no que tange os valores da pessoa humana e da família, que embora sejam conceitos juridicamente indeterminados e caiba regulamentação legal são normas constitucionais e, portanto, dotadas de eficácia imediata.

Nos reality shows, as provas e conteúdos vexatórios, bem como, a instrumentalização da pessoa para fins de mero entretenimento da audiência, ainda, que, com a autorização dos participantes corresponde a abuso do direito de liberdade de programação pela violação ao princípio da dignidade da pessoa humana, cabendo ao Estado adotar as medidas cabíveis para impedi-las.

Parece que cabe ao Estado-Legislador na conformação constitucional regulamentar o exercício do direito de programação no caso dos reality shows, impondo as restrições e sanções cabíveis para as provas e conteúdos vexatórios ou aquelas que de qualquer forma gere a instrumentalização da pessoa para fins de mero entretenimento da audiência, porém, conforme demonstrado há uma contínua omissão no tema.

Sob tal viés, cabe igualmente no controle de constitucionalidade realizado pela jurisdição constitucional promover a proteção dos bens e valores constitucionais redimensionando o exercício da atividade econômica e da liberdade de comunicação as finalidades e restrições determinadas pela ordem social de forma a garantir o exercício dos referidos direitos sem que viole a ordem jurídico-constitucional como um todo.

\section{REFERÊNCIAS}

ANDRADE, José Carlos Vieira de. Direitos Fundamentais na Contituição de 1976. Coimbra: Almedina, 2001.

. Os direitos, liberdades e garantias no âmbito das relações entre particulares. In: SARLET, Ingo Wolfgang (Org.). Constituição, Direitos Fundamentais e Direito Privado.2a.ed. Porto Alegre: Livraria do Advogado, 2006.

BARROSO, Luís Roberto. O direito constitucional e a efetividade de suas normas. Limites e possibilidades da Constituição brasileira. 7. ed. Rio de Janeiro: Renovar, 2003.

. Dez Anos da Constituição Brasileira de 1988. Revista de Direito Administrativo no 214.

. Liberdade de expressão, censura e controle da programação de televisão na Constituição de 1988. Revista dos Tribunais.São Paulo, ano 90, v. 790, p. 129-152, ago 2001.

BONAVIDES, Paulo. Do Estado Liberal ao Estado Social. 8 ed. São Paulo: Malheiros, 2007.

CANOTILHO, J. J. Gomes; MACHADO, Jónatas."Reality Shows” e liberdade de programação. Coimbra: Coimbra Editora, 2003.

CAPPELLETTI, Mauro. O Controle Judicial de Constitucionalidade das Leis no Direito Comparado. 1 ed. Porto Alegre: Sergio Antonio Fabris, 1984.

CARBONELL, Miguel. Neoconstitucionalismo(s). 1 ed. Madrid: Editorial Trotta, 2003. 
CARVELLI, Urbano. SCHOOL, Sandra. Evolução Histórica dos Direitos Fundamentais: Da Antiguidade até as Primeiras Importantes Declarações Nacionais de Direito. Revista de Informação Legislativa, Brasilia, a. 48 n. 191 jul/set 2011.

CASTELLS, Manuel. O poder da identidade. São Paulo: Paz e Terra, 2000.

CASTRO, Carlos Roberto Siqueira. A Constituição Aberta e os Direitos Fundamentais: ensaios sobre o constitucionalismo pós-moderno e comunitário. Rio de Janeiro: Forense, 2010.

COELHO, Rosa Júlia Plá. Mecanismos de Proteção dos Direitos Fundamentais.1 ed. Brasília: Ordem dos Advogados do Brasil, 2005.

DALLARI, Dalmo de Abreu. Estado de Direito e Direitos Fundamentais in: AMLEIDA FILHO, Agassiz de. CRUZ, Danielle da Rocha (Coord). Estado de direito e direitos fundamentais: homenagem ao jurista Mário Moacyr Porto. Rio de Janeiro: Forense, 2005.

DIMOULIS, Dimitri. MARTINS, Leonardo. Teoria Geral dos Direitos Fundamentais. São Paulo: Editora Revista dos Tribunais, 2008.

FERRAJOLI, Luigi. Derechos e Garantias: La ley del mais débil. 1 ed. Madrid: Trotta, 1999.

GARCIA, Deomara Cristina Damasceno; VIEIRA, Antoniella Santos; PIRES, Cristiane Carneiro.A explosão do fenômeno: reality show in: Revista de História e Teorias da Comunicação, Universidade da Beira Interior, Portugal, 2006.

HESSE, Konrad. A força normativa da Constituição. Porto Alegre: Sergio Antonio Fabris Ed., 1991.

LASSALLE, Ferdinand. Que é uma Constituição. São Paulo: Edições e Publicações Brasil, 1933.

LUÑO, Antonio Enrique Perez. Los Derechos Fundamentales. Madrid: Tecnos, 2004.

SARLET, Ingo Wolfgang.Op. cit. p. 42-43.

MENDES, Gilmar Ferreira. Controle de Constitucionalidade na Alemanha: A Declaração de Nulidade da Lei Inconstitucional, a Interpretação Conforme à Constituição e a Declaração de Constitucionalidade da Lei na Jurisprudência da Corte Constitucional Alemãin: Revista de Direito Administrativo, $\mathrm{n}^{\circ}$ 193, 1993.

MENDES, Gilmar Ferreira; BRANCO, Paulo Gustavo Gonet.Curso de Direito Constitucional. São Paulo: Saraiva, 2014.

MORAES, Maria Celina Bodin de. Constituição e Direito Civil: Tendências in: Revista dos Tribunais. Vol. 779 set. 2000.

MOREIRA, Ação Civil Pública e Programação de TV.Revista de Direito Administrativo, 201.Rio de Janeiro, jul/set, 1995.

MIRANDA, Jorge. Os Direitos Fundamentais- sua dimensão individual e social.Revista dos Tribunais, out/dez, Recife, 1992. 
SAMPAIO, José Adércio Leite. Mito e História da Constituição: Prenúncios Sobre a Constitucionalização do Direito in: SOUZA NETO, Cláudio Pereira e SARMENTO, Daniel. SARMENTO, Daniel e SOUZA NETO, Cláudio Pereira de (Orgs). A Constitucionalização do Direito: Fundamentos Teóricos e Aplicações Específicas. Rio de Janeiro: Lumen Juris, 2007.

SARLET, Ingo Wolfgang. Dignidade da pessoa humana e direitos fundamentais na Constituição Federal de 1988. Porto Alegre: Livraria do Advogado, 2001.

. As Dimensões da Dignidade da Pessoa Humana: Construindo uma compreensão jurídicoconstitucional necessária e possível. Revista Brasileira de Direito Constitucional, n. 09 jan/jul 2007 ,

SARMENTO, Daniel. Direitos Fundamentais e Relações Privadas. Rio de Janeiro: Lumen Juris, 2004.

Filosofia e Teoria Constitucional Contemporânea. Rio de Janeiro: Lumen Juris, 2009.

Direitos Fundamentais e Relações Privadas. Rio de Janeiro: Lumen Juris, 2004.

SILVA, José Afonso da. Aplicabilidade das normas constitucionais. 7. ed. São Paulo: Malheiros, 2008.

Curso de Direito Constitucional Positivo. 35. ed., rev. e atualizada até a emenda constitucional nº 68. São Paulo: Malheiros, 2012.

SOUZA NETO, Cláudio Pereira de; SARMENTO, Daniel (orgs.). A constitucionalização do direito: fundamentos teóricos e aplicações específicas. Rio de Janeiro: Lumen Juris, 2007. . Jurisdição, Democracia e Racionalidade Prática. Rio de Janeiro: Renovar, 2002.

TAVARES, Marco Aurélio Romagnloi. Ativismo judicial e políticas públicas: direitos fundamentais. Porto Alegre: Sergio Antonio Fabris, 2011.

TORRES, Marcelo Nóbrega da Câmara. Direitos sociais. Brasília: Senado Federal, 1987.

ZAGREBELSKY, G.El Derecho Dúctil: ley, derechos y justicia. 4 ed. Madrid: Editorial Trotta, 2002.

VIEIRA, Oscar Vilhena. A Constituição e sua Reserva de Justiça: Um Ensaio Sobre Os Limites Materiais Ao Poder de Reforma.São Paulo: Malheiros, 1999.

SANCHÍS, Luis Prietro. Sobre el Neoconstitucionalismo y Sus Implicaciones in: Justicia Constitucional y Derechos Fundamentales. Madrid: Trotta, 2003. 